\title{
Research on Investment Performance of Venture Capital Network Community in the Internet Industry
}

\author{
Xiaojie Pei $\mathbb{D}$ and Xinghua Dang \\ School of Economics and Management, Xi'an University of Technology, Xi'an 710054, China \\ Correspondence should be addressed to Xiaojie Pei; peixiaojie2020@yeah.net
}

Received 25 November 2021; Revised 27 December 2021; Accepted 3 January 2022; Published 20 January 2022

Academic Editor: Hasan Ali Khattak

Copyright (C) 2022 Xiaojie Pei and Xinghua Dang. This is an open access article distributed under the Creative Commons Attribution License, which permits unrestricted use, distribution, and reproduction in any medium, provided the original work is properly cited.

\begin{abstract}
Venture capital has emerged as an important intermediary in financial markets, providing capital to young high-technology firms that might have otherwise gone unfunded. Venture capitalists have developed a variety of mechanisms to overcome the problems that emerge at each stage of the investment process. This study selected the China Venture (CV) source database for venture capital (VC) research in the Chinese Internet industry and extracted information on investment time, VC firms, and investment amount. Combining theoretical analysis and empirical research, the differences between the leader community and the selforganizing community in the Chinese Internet industry are analyzed and the reasons and paths leading to the change of investment performance are determined. It is found that the information dissemination of core nodes promotes the information dissemination of leaders' communities and the two kinds of organizational learning have different effects on investment performance in the two communities. Under experimental learning and information dissemination, the investment performance of the leader community is greater than the self-organizing community. The outcomes of this research can be used as a reference for the sustainable development of the Chinese Internet industry.
\end{abstract}

\section{Introduction}

Over the past 30 years, VC has been an important source of financing for innovative companies. Firms supported by VC, including Apple, Amazon, Facebook, Intel, Google, and Microsoft, have a large impact on the global economy. The Chinese Internet industry supported by VC includes online games, e-commerce, social communities, electronic payments, mobile Internet, big data, sharing economy, and others. Internet industry start-up firms depend on VC to provide funds [1], social resources, technology, and business resources [2]. However, VC holds the characteristics such as high risk and low liquidity. With the expansion of the number and scale of VC, Chinese VC firms have formed a network through joint investment in the Internet industry to avoid risks and share resources. It is found that the community in the VC network can improve investment performance. To analyze the benefits of a network community to VC firms from a new perspective and ensure the healthy and sustainable development of the Internet industry, it is necessary to distinguish network communities and investment performance. Therefore, it is of practical significance to study the causes of investment performance differences.

Networks communities also feature prominently in the VC industry [3]. The network community can promote the development of VC firms, providing resources including information for VC firms [4]. VC firms hope to obtain detailed information about selecting projects before investment and postinvestment management to deal with the uncertainty of investment projects. Information dissemination is closely related to organizational learning [5]. Therefore, information dissemination and organizational learning have become the key factors affecting investment performance in network communities.

Network community's characteristic is internal close ties; there are no existing strict regulations and hierarchical control. Therefore, a network community can lay the foundation for information dissemination and improve 
community performance. Powell [6] believed that strategic alliance network ties as a channel of information dissemination are convenient for localized information spillover and that information dissemination in dense scientific research networks will promote the increase of communication capacity [7] and knowledge overlap. The existing literature shows that the network community changes the network community performance by changing enterprise capability [7] and information dissemination cost [8]. Scholars believe that not all networks provide equal benefits for their members [9]. Therefore, leader community and self-organizing community [10] should express different community performances. Although the existing studies from the social network theory or resource-based theory agree that information dissemination is the link between the network community and investment performance and the value-added of information in the dissemination has an impact on the network performance, there is no further analysis on the difference in investment performance caused by information dissemination in different types of VC communities. It also does not analyze the difference in the investment performance of different types of network communities based on the combination of social network theory and resource-based theory. Therefore, it is necessary to combine social network theory with resource-based theory to explore the reasons for the difference in investment performance between two types of network communities.

We should divide information dissemination for further research. The main work and capabilities of VC firms are focused on screening investment projects and postinvestment management [11]. Therefore, we divided information into project information and experience information according to content. We consider that project information dissemination refers to the dissemination of procedural and written information, such as evaluation indicators, screening criteria, and contract formulation required in the project screening stage. We define experience information dissemination as the dissemination of tacit information such as operation guidance, market development, and consulting services for the invested enterprises in the later management stage. Therefore, these two kinds of information can be categorized as explicit and implicit information, respectively.

Organizational learning leads to capability change by changing the knowledge base, and then capability affects performance. Leviathan and March [12] believed that new external knowledge can update the existing knowledge base in the R\&D alliance. Therefore, organizational learning can change the level of enterprise knowledge [13]. From the perspective of resource-based theory, the improvement of knowledge level can promote organizational learning ability. Fraj et al. [14] described that organizational learning is acquiring, identifying, integrating, and using the acquired knowledge that can improve internal skills and adapt to the changes of the external environment. Therefore, most organizational learning models believe that learning will have a long-term positive impact on performance [15]. VC firms also believe that part of the reason for the improvement of performance is team organizational learning [16]. And organizational learning will lead to the change of ability, which eventually affects performance. However, there are also objections. Huber pointed out that learning does not always improve learners' efficiency [17]. Firms may learn something objectively incorrect. Different types of organizational learning are not equally related to capability development. Therefore, Zahra et al. [18] carried out further research and divided organizational learning into acquisition learning and experimental learning to explore the impact of organizational learning on performance. They defined acquisition learning as learning other people's experiences by acquiring and internalizing the external knowledge existing in its boundary. Experimental learning is defined as learning one's own experience by repeating activities and adapting to experience. Moreover, the existing literature uses the resource-based theory to explain the reasons for the improvement of investment performance caused by organizational learning under the assumption that knowledge or information already exists. However, they rarely discuss how to obtain information. Therefore, this study tries to combine the acquisition of information using the social network theory and explains the relationship between information dissemination, organizational learning, and investment performance in two theoretical frameworks.

The rest of the manuscript is organized as follows. In Section 2, the theoretical development of VC is described and hypotheses are defined. In Section 3, the research design process is illustrated. Section 4 provides a detailed analysis of the obtained results. Section 5 is about the discussion, and the conclusions and limitations are presented in Section 6.

\section{Theoretical Development and Hypothesis}

2.1. Investment Performance of VC Network Community. The project information can change the investment performance of the network community. First, project information with explicit characteristics in the community is easy to overflow [19], which improves the project screening and evaluation capabilities of $\mathrm{VC}$ firms and then improves their own performance [20], resulting in the improvement of community performance [21]. Second, the network community limits the entry of "fresh project information" owing to forming fixed and conservative cooperation norms [7], which hinder the improvement of the ability and finally lead to the difficulty in improving the network community investment performance. Therefore, project information dissemination has an inverted U-shaped impact on network community information dissemination.

The experience information can change the investment performance of the network community. Close ties in the network community lead to multiple redundant relations, which are conducive to strengthening the implicit experience information dissemination [22] and reorganization, which has a positive impact on the investment performance of the whole community. Second, the tight connections of the network community lead to a highly similar knowledge base, which makes it difficult to produce experience information spillover [23]. Without the generation of new 
experiences, there will be no ability to improve information, let alone the investment performance of the network community. Therefore, experience information dissemination has an inverted $\mathrm{U}$-shaped impact on the performance of network community investment.

Acquisition learning and experimental learning change project information dissemination and affect the network community investment performance. First, VC firms use acquisition learning to allocate, update, and integrate project information causing spillover and then enhance the selection and evaluation ability of VC firms. Eventually, the community investment performance is improved. Second, in the practice of investment projects, VC firms will generate "inspiration" combination specific environment with their own investment experience [24]. This kind of project information needs to be obtained through experimental learning. But in practice, in the process of joint investment, because of VC firms' own conditions or locating in different cities, it is difficult to participate in the project review and screening on-site. Therefore, the effect of experimental learning on project information dissemination is not obvious on the investment performance of firms and network communities. Therefore, acquisition learning changes project information dissemination and then positively affects investment performance while experimental learning has no significant effect.

Acquisition learning and experimental learning change experience information dissemination and affect the network community investment performance. First, implicit experience information often can not adapt to the specific organizational environment and is difficult to spill over only by reading or observation. Therefore, under acquisition learning, the experience information dissemination has a limited impact on firm and community investment performance. Second, experimental learning itself is a process of repeated practice of experience information [25], which helps for experience information value-added and VC firms' ability improvement. Therefore, experimental learning changes experience information dissemination and positively affects the investment performance of the network community. However, the effect of acquisition learning is not significant.

2.2. Leader Community Investment Performance. The firm with a high degree of centrality in the community is called the core node in this study. The core node influences the dissemination of leaders' community project information by changing their project information dissemination. In terms of node attributes, the core node plays a strong communication leadership role [26] and controls coordination ability [27]. In summary, the core node becomes an information filter. However, in terms of relationship attributes, the core node is widely connected with other nodes and strictly controls the dissemination of project information. This kind of connection is regarded as a "closed pipeline" to ensure that only specific parties benefit from the information exchanged [23]. Therefore, in the dissemination process, the project information decline is reduced, and its quality and quantity are guaranteed. Then, the uncertainty of investment return potential is reduced. Therefore, the core nodes in the leader community play a role in promoting the dissemination of project information.

The core node affects the experience information dissemination of the leader community by changing its own experience information dissemination. In terms of node attributes, the core node acquires better network community location and control ability, which increase the innovation of experience information in practice. The core node gives full play to the role of "technical gatekeeper" [28] and finally promotes the dissemination of experience information in the leader community. From the perspective of relationship attributes, a "closed pipeline" could target transfer experience information and reduce cost and time, eventually increasing effective postinvestment participation. By comprehensively investigating the node attributes and relationship attributes, the following assumptions are obtained:

$\mathrm{H} 1$ : the information dissemination of the core node in the leader community promotes the information dissemination of the network community.

H1a: the project information dissemination of the core node in the leader community promotes the project information dissemination of the network community.

H1b: the experience information dissemination of the core node in the leader community promotes the experience information dissemination of the network community.

The core nodes affect the role of acquisition learning on information dissemination in two aspects. First, the core node can be located in the center of the community, has very strong project screening experience and postinvestment management experience, widens the difference in experience and skills with other nodes, and plays a catalytic role in the development of acquisition learning [29]. Second, the core node occupies a high position in the network community and has high credibility, greatly reducing the uncertainty and fuzziness of project information and experience information dissemination, which could increase the quality of information obtained through acquisition learning and improve the feasibility of investment suggestions and effective postinvestment participation.

The core nodes affect the role of community experimental learning on information dissemination in two aspects. First, the large difference between the core node and other nodes can promote exploratory experimental learning. Second, the core node occupies a high network community position, can control other nodes, create more opportunities for promoting experimental learning actively looking for knowledge and technology expansion, which is conducive to experimental learning to trial error and adapting experience, improve the dissemination quality of their project information and experience information, and reduce the uncertainty during investment. 
From these capabilities of the core node, it can be inferred that the leader community is full of competition and cooperation. There is a cooperative relationship between the core node and the noncore node. Then, there is a competitive relationship between noncore nodes. The greater the difference of degree centrality, the more intense is the competition and cooperation. Therefore, the following assumptions are made:

$\mathrm{H} 2$ : the leader community investment performance caused by information dissemination under experimental learning is greater than that caused by information dissemination under acquisition learning.

\subsection{Self-Organizing Community Investment Performance.} The investment performance formation of the self-organizing network community conforms to the formation rule of network community investment performance and also has its particularity. From the perspective of relationship attributes, the impact of the self-organizing community project information dissemination on investment performance is divided into two aspects. First, members of the selforganizing community follow their own rules, practices, and procedures. After many joint investments, the self-organizing community members have formed a strong sense of trust and worked closely when necessary without formal hierarchical control. Therefore, there is no significant power difference in the self-organizing network community. The tie between members is like a "leaky pipe," and everyone gets "irrigation" [23]. Second, it can hinder the information dissemination behavior that deviates from the norms, such as overcoming free-riding behavior. Third, multiple redundant paths shorten the distance between participants and promote faster and more reliable information flow. The final result is that the project information continues to overflow in the dissemination process. The spillover of project information in self-organizing communities will improve their investment performance, which affect the investment performance of communities.

From the perspective of relationship attributes, the role of experience information dissemination in a self-organizing community on investment performance is divided into two aspects. First, the connection relationship between members of the self-organizing community is relatively equal. The experience information needs to constantly try an error in practice to adapt to the changing external environment. Therefore, the equal relationship will not hinder the dissemination of experience information and reduce the dissemination cost, and the dissemination scope expands. Second, the nonhierarchical connection of a self-organizing community is conducive to the overflow of experience information. The spillover of experience information in selforganizing communities will improve their investment performance, which affects the investment performance of communities.

The organizational learning of a self-organizing community also has its characteristics. First, the members of the self-organizing community have a similar degree of centrality and nonhierarchical control. VC firms only invest less capital, energy, and time to establish a formal supervision mechanism. Similar degree centrality means that the cognitive distance between members is low [30], which is conducive to community members to adopt acquisition learning and experimental learning. Thus, it can save the cost of information dissemination and effectively improve the lack of information in the VC process. Second, similar degree centrality and no obvious power asymmetry means that community members are more connected with each other and less connected with the outside world, which reflects more closed. Members of self-organizing communities form strong norms and share the same basic model, which strengthens the tendency of members' preference for homogeneity [31], resulting in the stability of communities. Therefore, VC firms prefer to retain the existing information resource base rather than obtain new information resources. All of these will not cause strong requirements for experimental learning. Therefore, the following assumptions are made:

H3: the impact of information dissemination on the investment performance of self-organizing communities under acquisition learning is greater than that under experimental learning.

From the perspective of the joint action of node spillover and relationship spillover, the leader community can hold both node spillover and relationship spillover effects, while the self-organizing community can only get relationship spillover effects. Therefore, the investment performance of the leader community is higher than that of a self-organizing community. Therefore, the following assumptions are made:

$\mathrm{H} 4$ : the investment performance of the leader community is higher than that of a self-organizing community.

\section{Research Design}

3.1. Data Sources. This study selected the CV (China Venture) source database for VC research in China Internet industry. We extracted information on investment time, VC firms, investment amount, IPO or M\&A, etc. We also collected basic information about the fund management scale of invested firms. The VC in China appeared around 1990. The time to form the VC network and extract the community was about 2006 . Thus, our sample period is from January 1, 2006, to December 31, 2018. The final sample included 734 VC firms and 989 rounds of joint ventures. We used three-year time windows to calculate the impact of information dissemination on community performance. First, we should form a network community. We selected all joint investment information for 2006-2008 time windows in the CV source database. Firms involved in joint investment were coded and then were entered into the corresponding location of the UCINET 6.560 matrix according to the joint investment relationship. Thus, the VC network was formed [32]. Second, the GN algorithm is used to extract network communities. It already exists in UCINET 6.560. In our study, the network community size is set greater than or 
equal to 4 . Leader community and self-organizing community are classified according to the method of $\mathrm{Fu}$ et al. [10]. Finally, according to the divided communities, the information dissemination values of each network community in the 2006-2008 time windows are found. Meanwhile, we calculate the performance of the community in the 2007-2009 time windows. Then, the regression analysis can be carried out by pairing the calculated information dissemination values of each network community with the community performance. A total of 136 network communities were detected, including 90 leader communities and 46 self-organizing communities.

3.2. Variables and Measures. In this study, the dependent variable is community performance. The independent variable examines project information and experience information dissemination whereas the moderator variable examines organizational learning. Some community-level variables are taken as control variables.

3.2.1. Independent Variable. The dependent variable is VC network community investment performance. The exit method is adopted to indirectly measure the investment return of the firm [33]. The two most profitable exits for VC firms are IPO and M\&A. Therefore, this study adopted the ratio of the quantity of IPO and M\&A to the investment quantity of $\mathrm{VC}$ firms as the investment performance of $\mathrm{VC}$ firms. Based on the research conclusion of Shore et al. [34], this study set the investment performance of the community as a whole and considered the average of the sum of investment performance of all firms in the community.

3.2.2. Dependent Variable. The first dependent variable is project information dissemination. We measured the average value of the increment sum of all firm investment industry types in the community as project information dissemination, which is mainly divided into three steps to obtain the measurement method. First, the project information is the screening and evaluation method of a certain industry project. The research conclusion of Gupta and Sapienza [32] is adopted to represent project information by the type of investment industry. Second, after investigating the spread of enterprise VC practice, Gaba and Meyer [35] considered intragroup communication as dissemination from previous adopters to future adopters in the group. Thus, at time $T+1$, the firms in the community have invested in new industries, which represents the adoption of information from previous projects' information at time $T$. This study takes the investment increment of the firm to the industry at time $T+1$ as the measure of project information dissemination. Finally, referring to the research ideas of Shore et al. [34], the network is seen as a whole. Therefore, the result at the collective level is the accumulation of the results of these measures. We took community project information dissemination as a whole and considers that it is equal to the average value of project information dissemination of all community members.
The second dependent variable is the experience information dissemination. We measured the average value of the sum of incremental investment enterprises of all community members in the community as the experience information dissemination, which is mainly divided into three steps to obtain the measurement method. First, the experience information is value-added services for invested enterprises. We measured the experience information using the means of Hochberg et al. [36]. It is expressed in terms of the cumulative number of invested enterprises. Second, we adopted the method of Gaba and Meyer [35]. They considered that in time $T+1$ community firms invested in new enterprises to represent the adoption of previous experience information at time $T$. In this paper, the increment of investment enterprise at time $T+1$ is taken as the measure of experience information dissemination. Finally, referring to the research ideas of Shore et al. [34], the experience information dissemination of community is taken as a whole and the sum of all community members information dissemination is averaged.

\subsubsection{Moderator Variable. The first moderator variable is} acquisition learning which is measured by the average of the sum of community member acquisition learning and is mainly divided into three steps to obtain the measuring method. First, learning is the process of creating knowledge through the transformation of experience [37], so scholars take the experience as a measure of learning results [38]. Second, Yang et al. [39] believed that the experience of acquisition learning can be represented by the frequency of joint investment. Therefore, this study measures acquisition learning by the frequency of joint investment. Finally, we take community acquisition learning as a whole and express it by the average of the sum of acquisition learning of all community members. For example, taking 2006-2008 as the starting time window, we regarded the joint and total investment amount of the firms before this period as zero. Acquisition learning of firms in the 2007-2009 time window only considers the joint and total investment amount in the 2006-2008 time windows. The acquisition learning in 2008-2010 time windows is the ratio of the sum of the joint investment to the sum of total investment in the 2006-2009 and the 2007-2009 time windows.

The second moderator variable is experimental learning. The experimental learning is measured by the average of the sum of the community members' experimental learning, which is mainly divided into three steps to obtain the measuring method. First, the learning results are also measured by the experience [38]. Second, Yang et al. [39] believed that the number of investment repeats is an important reflection of the experimental learning process. Therefore, this study adopted the amount of investment completed before the focus investment to measure the experimental learning. Finally, we take community experimental learning as a whole, and we obtain the value as the average of the sum of experimental learning of all community members. For example, the experimental learning from time window 2006 to 2008 is zero. The experimental 
learning in 2008-2010 time windows is the sum of the total investment in the 2006-2008 and the 2007-2009 time windows.

3.2.4. Control Variables. The first control variable is the community scale. Community size will affect the communication and investment decisions of members of the community. We used the number of members in a community as a measure. The second control variable is resource endowment. The resource endowment of VC firms affects their VC activities. We used the logarithmic transformation of the number of managed funds (in millions) as the measurement method. This study refers to the research idea of Shore et al. [34], which states that the resource endowment of a community is the average value of the sum of the members' resource endowment.

\section{Data Analysis and Results}

4.1. Descriptive Statistics. There is a high correlation between some dependent variables, independent variables, control variables, and moderator variables. The statistical results of the sample are given in Table 1.

4.2. Multiple Regression Analysis. The multicollinearity problem exists between project information dissemination and experience information dissemination and the acquisition learning and experimental learning too. Therefore, ridge regression analysis [40] is used to ensure the authenticity of the results. Meanwhile, all variables are standardized before calculation. This method was used in all regression analyses below. The results of the total sample regression analysis are shown in Table 2.

In model 1, community size has a negative impact on investment performance. Community resource endowment has a positive impact on investment performance. But neither result was significant. In model 2, community project information dissemination has a significant inverted U-shaped impact on community investment performance. Community experience information dissemination has a significant inverted U-shaped impact on community investment performance. In model 3, acquisition learning has a positive impact on project information dissemination and investment performance. Acquisition learning has no significant impact on experience information and investment performance. In model 4, experimental learning has no significant impact on project information dissemination and investment performance. In contrast, experimental learning has a significant positive impact on experience information dissemination and investment performance.

In this study, the communities are divided into 90 leader communities and 46 self-organizing communities by using the division criteria of Fu et al. [10]. We defined the core node in that its degree centrality is higher than the leader community mean degree centrality 3 standard deviations [41]. Table 3 shows the results of information dissemination of core nodes and community information dissemination of the leader community.
In Table 3, both core node project information dissemination and experience information dissemination have a positive impact on leader community information dissemination. Therefore, hypothesis $\mathrm{H} 1$ is supported. In other words, the core node plays an important role in the leader community. The direction and speed of the leader community development will be affected by the core nodes. We boldly infer that in some extreme environments, the core node could hinder the performance of the leader community. Models $7-10$ in Table 4 are the results of the leader community regression models. Models 11-14 are self-organizing community regression model results. The changing trend of leader community regression model results is the same as that of the general model test. However, the results of the self-organizing community regression model are different from those of the general model. Both acquisition learning and experimental learning have a significant impact on information dissemination and investment performance. The main reason is that there is no obvious difference among members in the selforganizing community. The community heterogeneity is low. There is no more fresh information in the self-organizing community. Thus, its uncertainty is reduced. Both acquisition learning and experimental learning can improve the ability of VC firms and their investment performance. Finally, the performance of community investment is improved.

Table 5 shows the mean and variance of the variables of leader community and self-organizing community. According to the regression results in Table 4, the regression equations of information dissemination of leader community and self-organizing community can be obtained, respectively. We put the mean value in Table 5 into the equation to obtain the result as in Table 6.

In the leader community, project information and experience information have different results of investment performance under different organizational learning. The results show that the effect of information dissemination on leader community investment performance under experimental learning is greater than that under acquisition learning. Therefore, hypothesis $\mathrm{H} 2$ is supported. In the selforganizing community, the project information and experience information on the investment performance under acquisition learning are greater than those under experimental learning. Therefore, hypothesis H3 is also supported.

Under experimental learning and information dissemination, the investment performance of the leader community is greater than that of a self-organizing community. However, under the acquisition learning and information dissemination, the investment performance of a self-organizing community is greater than that of a leader community. Therefore, Hypothesis H4 is partially supported. The main reason is the existence of core nodes in the leader community and the heterogeneity of network community relations. The core node is in the best position of the community, resulting in a higher ability to identify, filter, and absorb knowledge [28], and a higher knowledge base. The widening of the knowledge gap can increase the driving force of experimental learning. Core node actively uses trial error and experimental methods to increase its project information and experience information and promote 
TABle 1: Descriptive statistics of variables and Pearson correlation matrix.

\begin{tabular}{|c|c|c|c|c|c|c|c|c|c|}
\hline Variable name & Average & $\begin{array}{l}\text { Standard } \\
\text { deviation }\end{array}$ & Observed & \multicolumn{6}{|c|}{ Pearson correlation matrix } \\
\hline mination & 0.302 & 0.067 & 136 & 1 & & & & & \\
\hline $\begin{array}{l}\text { Experience information } \\
\text { dissemination }\end{array}$ & 3.085 & 1.526 & 136 & $0.423^{*}$ & 1 & & & & \\
\hline Acquisition learning & 1.110 & 0.041 & 136 & $0.486^{* *}$ & -0.349 & 1 & & & \\
\hline Experimental learning & 1.730 & 0.367 & 136 & 0.327 & $0.546^{* *}$ & $0.463^{*}$ & 1 & & \\
\hline Community scale & 1.702 & 0.231 & 136 & -0.357 & 0.079 & $0.438^{*}$ & -0.189 & 1 & \\
\hline Resource endowment & 4.242 & 1.258 & 136 & 0.323 & 0.012 & 0.188 & 0.398 & -0.182 & 1 \\
\hline $\begin{array}{l}\text { Community investment } \\
\text { performance }\end{array}$ & 0.405 & 0.193 & 136 & 0.199 & 0.652 & 0.633 & $0.468^{*}$ & 0.345 & 0.138 \\
\hline
\end{tabular}

Note: ${ }^{* *}$ and ${ }^{*}$ indicate significant correlation at 0.05 and 0.1 levels, respectively.

TABLE 2: Results of the total sample regression model.

\begin{tabular}{|c|c|c|c|c|}
\hline Variables & Model 1 & Model 2 & Model 3 & Model 4 \\
\hline Community scale & -0.031 & -0.021 & -0.025 & -0.017 \\
\hline Community resource endowment & 0.005 & 0.009 & 0.014 & 0.016 \\
\hline Project information dissemination & & $0.146^{* *}$ & $0.137^{* *}$ & $0.142^{*}$ \\
\hline Project information dissemination ${ }^{2}$ & & $-0.033^{* *}$ & $-0.041^{* *}$ & $-0.052^{* *}$ \\
\hline Experience information dissemination & & $0.038^{*}$ & $0.024^{*}$ & $0.055^{* *}$ \\
\hline Experience information dissemination ${ }^{2}$ & & $-0.033^{* *}$ & $-0.030^{* *}$ & $-0.017^{* *}$ \\
\hline Acquisition learning & & & $0.039^{*}$ & \\
\hline Experimental learning & & & & $0.033^{* *}$ \\
\hline Project information dissemination $\times$ acquisition learning & & & $0.031^{*}$ & \\
\hline Project information dissemination ${ }^{2} \times$ acquisition learning & & & $-0.030^{*}$ & \\
\hline Experience information dissemination $\times$ acquisition learning & & & 0.010 & \\
\hline Experience information dissemination ${ }^{2} \times$ acquisition learning & & & -0.013 & \\
\hline Project information dissemination $\times$ experimental learning & & & & 0.011 \\
\hline Project information dissemination ${ }^{2} \times$ experimental learning & & & & -0.004 \\
\hline Experience information dissemination $\times$ experimental learning & & & & $0.015^{*}$ \\
\hline Experience information dissemination ${ }^{2} \times$ experimental learning & & & & $-0.007^{*}$ \\
\hline$R^{2}$ & 0.022 & 0.456 & 0.556 & 0.596 \\
\hline$\Delta R^{2}$ & 0.018 & 0.410 & 0.490 & 0.546 \\
\hline$F$ & 0.336 & $12.149^{* * *}$ & $7.123^{* * *}$ & $8.137^{* * *}$ \\
\hline K & 0.3 & 0.3 & 0.3 & 0.3 \\
\hline
\end{tabular}

Note: standard errors in parentheses. ${ }^{*} p<0.1,{ }^{* *} p<0.05,{ }^{* * *} p<0.01 . K$ is the value of ridge regression.

noncore nodes to surpass their limitations in screening projects and postinvestment management. The connection relationship of the network community caused by core nodes has become a "closed relationship." The information dissemination on it is reliable and exclusive, which could improve the quality of information. At the same time, the existence of core nodes will form a nonuniform network, which can spread information faster than the uniform network [9]. Then, the information dissemination time can be saved. Therefore, under the experimental learning and information dissemination, the investment performance of the leader community is higher than that of the self-organizing community without core nodes.
Information dissemination under acquisition learning makes the investment performance of a self-organizing community better than that of a leader community. The core nodes exist in the best network community position and can control the direction and number of information dissemination [42]. Therefore, the core node adopts the contraction strategy and strictly controls the information dissemination (including quantity and quality), which will reduce the investment performance of the leader community. However, there is no obvious degree of centrality difference between firms in the self-organizing community, and there is no control and restraint relationship. The whole community is in an atmosphere of low competition and low cooperation. 
TABLE 3: Regression results of information dissemination of core nodes in leader community.

\begin{tabular}{lcc}
\hline Variables & Model 5 & Model 6 \\
\hline Community scale & -0.243 & -0.157 \\
Community resource endowment & 0.214 & 0.113 \\
Core node project information dissemination & $0.315^{*}$ & \\
Core node experience information dissemination & & 0.523 \\
$R^{2}$ & 0.348 & 0.475 \\
$\Delta R^{2}$ & $3.879^{*}$ & 0.236 \\
$F$ & 0.2 & $4.125^{*}$ \\
$K$ & 0.2 \\
\hline
\end{tabular}

Note: standard errors in parentheses. ${ }^{*} p<0.1,{ }^{* *} p<0.05,{ }^{* * *} p<0.01 . K$ is the value of ridge regression.

TABLE 4: The investment performance of leader community and self-organizing community.

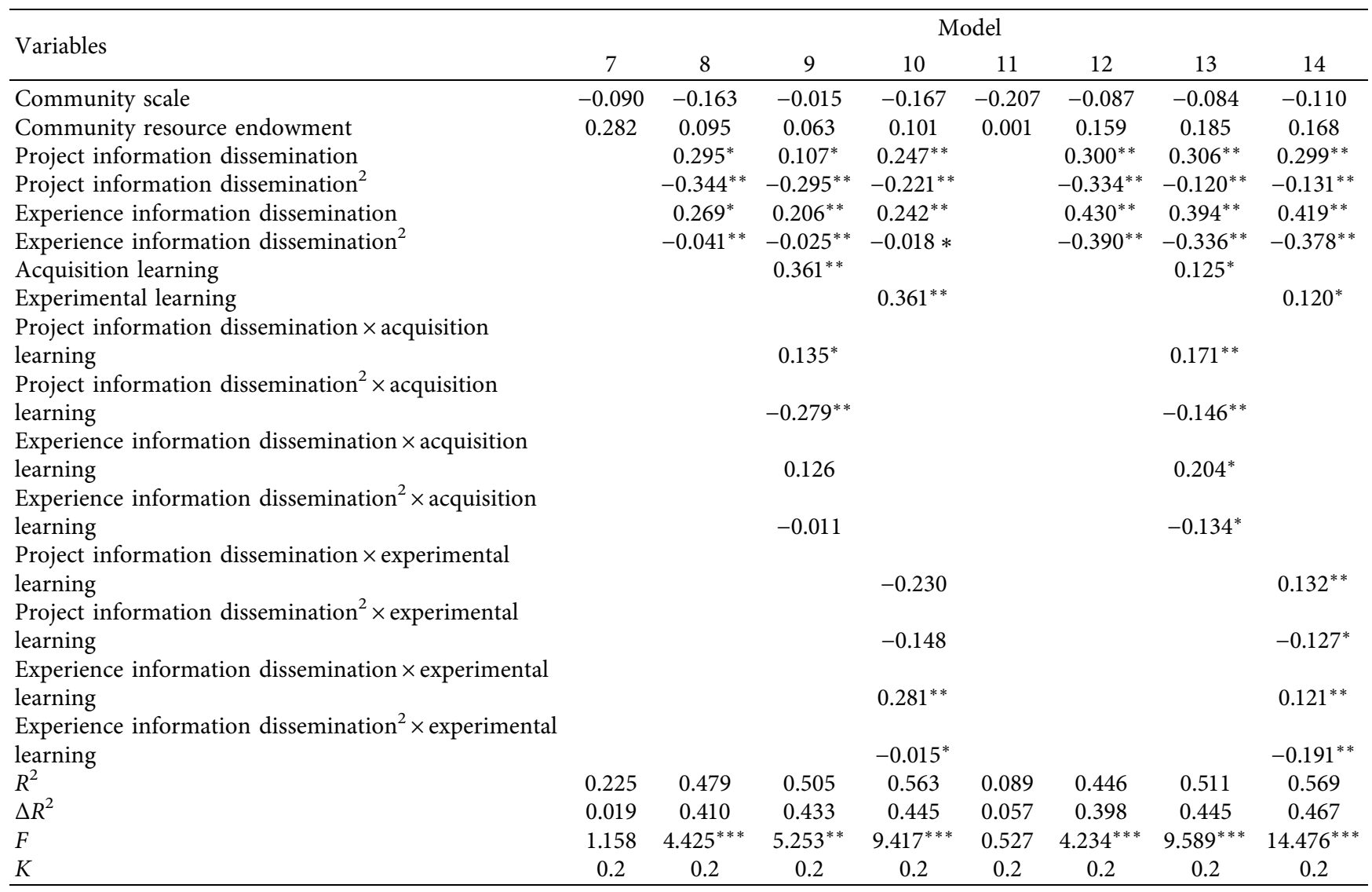

Note: standard errors in parentheses. ${ }^{*} p<0.1,{ }^{* *} p<0.05,{ }^{* * *} p<0.01 . K$ is the value of ridge regression.

Members focus on learning and improving the existing information and experience to maintain and improve their investment skills, to improve their investment performance. Therefore, members could obtain higher investment performance than before by only using acquisition learning. Hence, the investment performance of the leader community under the acquisition learning is lower than that of a self-organizing community.

\section{Discussion}

In this study, the relationship among information dissemination, organizational learning, and investment performance of the Internet industry VC network community is investigated and the following conclusions are drawn.
First, for the first time, we divide the information dissemination of the VC network community into project information dissemination and experience information dissemination. Then, combining social network theory and resource-based theory, we further analyzed the performance differences between the two types of network communities based on our previous research. We found the important role of the core node in the leader community. It is reported that the core node promotes its own two kinds of information dissemination because of its node attributes and relationship attributes, which promote the information dissemination of the whole community. The results of the current studies are consistent with the results of OwenSmith and Powell [23] on the core nodes in biotechnology networks. 
TABLE 5: Mean and variance of variables in leader and self-organizing community.

\begin{tabular}{lcccc}
\hline \multirow{2}{*}{ Variables } & \multicolumn{2}{c}{ Leader community } & \multicolumn{2}{c}{ Self-organizing community } \\
& Mean & Variance & Mean & 1.224 \\
Community scale & 2.001 & 0.365 & 2.120 & 0.057 \\
Community resource endowment & 5.269 & 1.331 & 0.085 & 1.257 \\
Project information dissemination & 0.456 & 0.134 & 0.824 & 0.021 \\
Experience information dissemination & 4.380 & 1.356 & 0.155 & 0.472 \\
Acquisition learning & 0.080 & 0.012 & 0.878 & 0.015 \\
Experimental learning & 2.335 & 1.578 & & 0.168 \\
\hline
\end{tabular}

TABLE 6: Investment performance of leader and self-organizing community.

\begin{tabular}{lcc}
\hline Community classification & Organizational learning & Investment performance \\
\hline \multirow{2}{*}{ Leader community } & Acquisition learning & 1.537 \\
& Experimental learning & 4.192 \\
Self-organizing community & Acquisition learning & 0.505 \\
& Experimental learning & 0.421 \\
\hline
\end{tabular}

Second, the main reason that VC firms gather to form a network community is to improve their project screening ability and postinvestment management ability. Therefore, organizational learning has become a decisive factor. The results show that in the leader community the investment performance under the experimental learning and information dissemination is higher than that under the acquisition learning and information dissemination. The main reason is the fact that not only does the core node promote the dissemination of the two kinds of information but also the existence of the core node leads to fierce competition and cooperation in the leader community. Therefore, the leader community needs to actively seek heterogeneous information to maintain and improve investment performance. At present, no similar research conclusion has been found in the research of the VC leader community. This study is an active attempt to study the VC network community from a mesoperspective.

Third, the impact of different organizational learning in self-organizing communities is also different. In the selforganizing community, the investment performance under the acquisition learning and information dissemination is higher than that under the experimental learning and information dissemination. The main reason is that the members of the self-organizing community have no hierarchical control and homogeneity preference, which results in no fierce competition and cooperation in the community. Therefore, members only need to maintain existing information resources rather than develop new information resources to maintain investment performance. At present, no similar research conclusion has been found in the research of the VC self-organizing community. This study is an active attempt to study the VC network community from a mesoperspective.

Last, under the experimental learning and information dissemination, the investment performance of the leader community is greater than that of a self-organizing community. However, under the acquisition learning and information dissemination, the investment performance of a self-organizing community is greater than that of a leader community. In Li et al.'s [43] research on the network community performance of scientific teams, it is concluded that the leader community performance is greater than the self-organizing community performance. However, his research is to measure the performance of the network community by adding and removing core nodes from the perspective of network topology. We examine the impact of organizational learning and information dissemination on investment performance in the Internet industry. Therefore, this study is a further development of Li et al.'s research.

In addition to the above theoretical contributions, this study also has certain practical significance for promoting Internet industry VC. The ultimate goal is to promote the development of the Internet industry. First, we need to pay attention to the importance of the core node in the leader community. We should give full play to the role of core nodes in promoting information dissemination. However, we should also be careful to prevent the core nodes from hindering the information dissemination of network communities for their strategic purposes. In a positive market environment, the government formulates a positive VC policy to stimulate the core nodes to play the role of an incubator.

Second, in the leader community, experimental learning is often used to improve investment performance. In the leader community, the existence of core nodes leads to the hierarchy existence of the community. Therefore, different levels are cooperative relations, while the same level is full of fierce competition. To obtain novel information, using experimental learning to promote community investment performance has become an inevitable choice. Therefore, closely following and imitating the core nodes in the leader community has become an important way to improve investment performance. At the same time, community members can transfer some interests if necessary in order to obtain joint investment with core nodes.

Third, in self-organizing communities, acquisition learning is often used to improve investment performance. Due to the nonhierarchical and homogeneous characteristics of self-organizing communities, there is no highly 
differentiated information base among community members. Therefore, members widely adopt acquisition learning to make up for the knowledge gap, enrich the knowledge base, and adapt to environmental changes, which is enough to ensure the stability or improvement of their investment performance. Moreover, reducing experimental learning can also reduce learning costs. Members of the self-organizing community maintain frequent communication and contact, such as actively participating in public project roadshows, VC salons, and VC lectures. Therefore, VC firms obtain as wide a range of $\mathrm{VC}$ information as possible through observation and listening to improve their performance.

\section{Conclusion}

This study empirically examines the investment performance of network communities among VC firms. We extracted information on investment time, VC firms, investment amount, and IPO and M\&A from the China Venture source database, analyzed the variations between the leader community and the self-organizing community in the Chinese Internet industry, and pointed out the reasons and paths that impact investment performance. It was concluded that the information dissemination of core nodes stimulates the information dissemination of leaders' communities. The two kinds of organizational learning have distinct impacts on investment performance in the two communities. Moreover, the investment performance of a leader community is greater than a self-organizing community. The outcomes of these studies can be used as a reference for the sustainable development of the Chinese Internet industry. However, this study still has some shortcomings. First, different types of network communities exist heterogeneously. Therefore, the speed of information dissemination could exist differently. If we adopted the simulation analysis method, the information dissemination could be refined for distinguishing the role of information dissemination on performance. Second, if we interpret the performance differences of network communities from other perspectives, there may be different conclusions. This analysis becomes the research direction in the future.

\section{Data Availability}

The data used to support the findings of this study are included within the article.

\section{Conflicts of Interest}

The authors declare that they have no conflicts of interest.

\section{Authors' Contributions}

Conceptualization was done by Xiaojie Pei and Xinghua Dang; methodology, Xinghua Dang; formal analysis, Xiaojie Pei; original draft preparation, Xiaojie Pei; reviewing and editing the manuscript, Xiaojie Pei.

\section{Acknowledgments}

This research was funded by the National Natural Science Foundation of China (NSFC) under grant no. 71572146 and Human and Social Sciences Research Youth Foundation West and Border Areas Project of the Education Ministry under grant no. 17XJC630010. The support is gratefully acknowledged.

\section{References}

[1] T. J. Gerpott, C. Niegel, Mobile business start-ups in Germany," The International Journal on Media Management, vol. 4, no. 4, pp. 235-247, 2002.

[2] W. B. Lowell, J. O. Fiet, D. D. Moesel, Reconsidering the venture capitalists value added proposition: an interorganizational learning perspective," Journal of Business Venturing, vol. 19, pp. 787-807, 2004.

[3] A. Bubna, S. R. Das, and N. prabhala, Venture Capital Communities, pp. 1-79, Social Science Electronic Publishing, New York, NY, USA, 2019.

[4] J. M. Podolny, "Networks as the pipes and prisms of the market," American Journal of Sociology, vol. 107, no. 1, pp. 33-60, 2001.

[5] A. Morrison, "Gatekeepers of knowledgewithin industrial districts: who they are, how they interact," Regional Studies, vol. 42, no. 6, pp. 817-835, 2008.

[6] W. W. Powell, "Inter-organizational collaboration in the biotechnology industry," Journal of Institutional Theoretical Economy, vol. 152, pp. 197-215, 1996.

[7] M. A. Mcfadyen, M. Semadeni, and A. A. Cannella, "Value of strong ties to disconnected others: examining knowledge creation in biomedicine," Organization Science, vol. 20, no. 3, pp. 552-564, 2009.

[8] T. Keil, "Building external corporate venturing capability," Journal of Management Studies, vol. 41, pp. 0022-2380, 2004.

[9] Z Liu, Y. C Lai, and N Ye, "Propagation and immunization of infection on general networks with both homogeneous and heterogeneous components," Physical review. E, Statistical, nonlinear, and soft matter physics, vol. 67, Article ID 031911, 2003.

[10] J. C. Fu, W. X. Zhang, and J. L. Wu, "Identification of leader and self-organizing communities in complex networks," Scientific Report, vol. 7, p. 704, 2017.

[11] S. N. Kaplan and P. Strömberg, "Venture capitalists as principals: contracting, screening, and monitoring," The American Economic Review, vol. 91, no. 2, pp. 426-430, 2001.

[12] D. A. Levinthal and J. G. March, "The myopia of learning," Review of. Strategic Management Journal, vol. 14, pp. 95-112, 1993.

[13] C. M. Fiol and M. A. Lyles, "Organizational learning," Academy of Management Review, vol. 10, no. 4, pp. 803-813, 1985.

[14] E. Fraj, J. Matute, and I. Melero, "Environmental strategies and organizational competitiveness in the hotel industry: the role of learning and innovation as determinants of environmental success," Tourism Management, vol. 46, pp. 30-42, 2015.

[15] J. Hagedoorn, "A note on international market leaders and networks of strategic technology partnering," Strategic Management Journal, vol. 16, no. 3, pp. 241-250, 1999.

[16] L. T. Perry, "The capital connection: how relationships between founders and venture capitalists affect innovation in 
new ventures," Academy of Management Perspectives, vol. 2, no. 3, pp. 205-212, 1988.

[17] G. P. Huber, "Organizational Learning: The Contributing Processes and the Literatures," Organization Science, vol. 2, pp. 188-215, 1991.

[18] S. A. Zahra, R. D. Ireland, and M. A. Hitt, "International expansion by new venture firms: international diversity, mode of market entry, technological learning, and performance," Academy of Management Journal, vol. 43, no. 5, pp. 925-950, 2000.

[19] J. Barney, "Firm resources and sustained competitive advantage," Journal of Management, vol. 17, no. 1, pp. 99-120, 1991.

[20] M. A. Peteraf, "The cornerstones of competitive advantage: a resource-based view," Strategic Management Journal, vol. 14, no. 3, pp. 179-191, 1993.

[21] T. C. Schelling, Micromotives and Macrobehavior, Norton, New York, NY, USA, 1978.

[22] D. Centola, "The spread of behavior in an online social network experiment," Science, vol. 329, no. 5996, pp. 1194-1197, 2010.

[23] J. Owen Smith and W. W. Powell, "Knowledge networks as channels and conduits: the effects of spillovers in the boston biotechnology community," Organization Science, vol. 15, no. 1, pp. 5-21, 2004.

[24] C. Y. Tsai, J. S. Horng, C. H. Liu, and D. C. Hu, "Work environment and atmosphere: the role of organizational support in the creativity performance of tourism and hospitality organizations," International Journal of Hospitality Management, vol. 46, pp. 26-35, 2015.

[25] D. C. Mowery, J. E. Oxley, and B. S. Silverman, "Strategic alliances and interfirm knowledge transfer," Strategic Management Journal, vol. 17, no. S2, pp. 77-91, 1996.

[26] A. Agrawal and R. Henderson, "Putting patents in context: exploring knowledge transfer from MIT," Management Science, vol. 48, no. 1, pp. 44-60, 2002.

[27] D. J. Teece, G. Pisano, and A. Shuen, "Dynamic capabilities and strategic management," Strategic Management Journal, vol. 18, no. 7, pp. 509-533, 1997.

[28] F. Munari, M. Sobrero, and A. Malipiero, "Absorptive capacity and localized spillovers: focal firms as technological gatekeepers in industrial districts," Industrial and Corporate Change, vol. 21, no. 2, pp. 429-462, 2012.

[29] H. Yang, Z. Lin, and M. W. Peng, "Behind acquisitions of alliance partners: exploratory learning and network embeddedness," Academy of Management Journal, vol. 54, no. 5, pp. 1069-1080, 2011.

[30] E. Giuliani and M. Bell, "The micro-determinants of mesolevel learning and innovation: evidence from a Chilean wine cluster," Research Policy, vol. 34, no. 1, pp. 47-68, 2005.

[31] G. Ahuja, F. Polidoro, and W. Mitchell, "Structural homophily or social asymmetry? The formation of alliances by poorly embedded firms," Strategic Management Journal, vol. 30, no. 9, pp. 941-958, 2009.

[32] A. K. Gupta and H. J. Sapienza, "Determinants of venture capital firms' preferences regarding the industry diversity and geographic scope of their investments," Journal of Business Venturing, vol. 7, no. 5, pp. 347-362, 1992.

[33] S. R. Das, H. Jo, and Y. Kim, "Polishing diamonds in the rough: the sources of syndicated venture performance," Journal of Financial Intermediation, vol. 20, no. 2, pp. 199-230, 2011.

[34] J. Shore, E. Bernstein, and D. Lazer, "Facts and Figuring: An Experimental Investigation of Network Structure and
Performance in Information and Solution Spaces," Organization Science, vol. 26, no. 5, pp. 1432-1446, 2015.

[35] V. Gaba and A. D. Meyer, "Crossing the organizational species barrier: How venture capital practices infiltrated the information technology sector," Academic Management Journal, vol. 51, no. 5, pp. 976-998, 2008.

[36] Y. V. Hochberg, A. Ljungqvist, and Y. Lu, "Whom you know matters: venture capital networks and investment performance," The Journal of Finance, vol. 62, no. 1, pp. 251-301, 2007.

[37] D. Kolb, "Experiential learning: experience as the source of learning and development," Journal of Organizational Behavior, vol. 8, pp. 359-360, 1984.

[38] M. Lyles, D. Li, and H. Yan, "Chinese outward foreign direct investment performance: the role of learning," Management and Organization Review, vol. 10, no. 3, pp. 411-437, 2014.

[39] Y. Yang, V. K. Narayanan, and S. Zahra, "Developing the selection and valuation capabilities through learning: the case of corporate venture capital," Journal of Business Venturing, vol. 24, no. 3, pp. 261-273, 2009.

[40] R. Levesque, SPSS Programming and Data Management, A guide for SPSS and SAS users, SPSS Inc, USA, 2005.

[41] J. Goldenberg and S. Efroni, "Using cellular automata modeling of the emergence of innovations," Technological Forecasting and Social Change, vol. 68, no. 3, pp. 293-308, 2001.

[42] E. Rogers, The Diffusion of Innovation, Free Press, New York, NY, USA, 1983.

[43] J. Li, J. Zhang, H. Li, and M. Jiang, "Network and community structure in a scientific team with high creative performance," Physica A: Statistical Mechanics and Its Applications, vol. 508, pp. 702-709, 2018. 